\title{
Effects of commercial soils on germination, early growth, and chlorophyll content of Aspilia africana, a medicinal plant
}

\author{
Denis Okello $\cdot$ Richard Komakech $\cdot$ Yong-Goo Kim • Endang Rahmat $\cdot$ Yuseong Chung Francis Omujal • \\ Youngmin Kang
}

Received: 9 March 2021 / Revised: 20 June 2021 / Accepted: 20 June 2021

(c) Korean Society for Plant Biotechnology

\begin{abstract}
Aspilia africana (Pers) C.D.Adams, a plant used for centuries in many African countries to treat diseases such as osteoporosis, malaria, tuberculosis, and diabetes, is of great pharmaceutical interest, yet there is limited scientific literature on its germination and growth. This research paper describes the effects of different commercial soils on the germination, growth, and chlorophyll content of $A$. africana. The germination parameters assessed included final germination percentage (FGP), mean germination time (MGT), and germination index (GI). Shoot length, leaf number, and fresh and dry weights were some of the parameters used to assess A. africana growth. The FGP was low and did not vary significantly; the MGT was $7 \sim 10$ days; and the GI was significantly higher in PPS soil at $4.61 \pm 0.332$ days. Aspilia africana plants in HS:PPS soil showed the best overall growth, producing the highest mean leaf number $(18.00 \pm$ 1.129), longest mean shoot length $(202.43 \pm 13.451 \mathrm{~mm})$, and highest mean fresh and dry weights $(7.08 \pm 1.061 \mathrm{~g}$ and
\end{abstract}

D. Okello $\cdot$ R. Komakech $\cdot$ Y.-G. Kim $\cdot$ E. Rahmat $\cdot$ Y. Chung $\cdot$ Y. Kang $(\bowtie)$

Herbal Medicine Resources Research Center, Korea Institute of Oriental Medicine (KIOM), 111 Geonjae-ro, Naju-si, Jeollanam-do 58245 , Republic of Korea

e-mail: ymkang@kiom.re.kr

D. Okello $\cdot$ E. Rahmat $\cdot$ Y. Kang

Korean Convergence Medicine Major, University of Science and Technology (UST), Republic of Korea

Y.-G. Kim

Biological Resource Center, Korea Research Institute of Bioscience and Biotechnology (KRIBB), Jeongeup 56212, Republic of Korea

D. Okello

Gombe Secondary School, P. O. Box, 192, Butambala/Mpigi,

Uganda, East Africa

R. Komakech · F. Omujal

Natural Chemotherapeutics Research Institute (NCRI), Ministry of Health, P.O. Box 4864, Kampala, Uganda
$0.629 \pm 0.112 \mathrm{~g}$, respectively). The highest chlorophyll content in leaves of $A$. africana under HS:PPS conditions suggested a higher photosynthetic potential of plants in this soil. The best growth performance of $A$. africana in the HS:PPS soil could be attributed to a higher amount of certain mineral nutrients such as nitrogen, potassium, and phosphorus in the HS:PPS soil compared to the other soil categories. It is unclear why the FGP of $A$. africana was low and we recommend an exclusive study to investigate this further.

Keywords Aspilia africana, Chlorophyll, Commercial soil, Growth, Seed germination

\section{Introduction}

Aspilia africana (Pers.) C. D. Adams is an important medicinal plant that belongs to the Asteraceae family (Okello et al. 2020). The plant has been in use for many years in different African communities for the treatment of many diseases including osteoporosis, stomach ache, diarrhea, cough, malaria, tuberculosis, gastric ulcers, sores, diabetes, febrile headaches, rheumatic pains, bee, scorpion and wasp stings, ear infections, and gonorrhea (Ajeigbe et al. 2014; Okello and Kang 2019b). It has a great wound healing potential and is also used as a contraceptive in some communities (Okello et al. 2020). The therapeutic attribute of the plant is due to its richness in a broad range of secondary metabolites including alkaloids, tannins, flavonoids, saponins, terpenoids, phenolic compounds, sterols and glycosides (Komakech et al. 2019).

According to the World Health Organization (WHO), over $80 \%$ of the human population throughout the world relies on traditional medicine for their primary healthcare needs (Okello and Kang 2019a). In many of the developing and developed countries, plant based medicines are becoming 
increasingly popular since they are more affordable and efficacious with less side effects compared to conventional medicines (Okello and Kang 2019b).

A. africana is a shrub that can grow up to a height of $2 \mathrm{~m}$ in soil of good nutritional content and water availability (Okello et al. 2020). The plant is indigenous to East Africa but occurs in farmlands, forest zones and wastelands in all regions of the savanna and tropical Africa (Komakech et al. 2019).

An important factor for seed germination and establishment of seedlings is soil type. The germination of seeds depend on soil attributes including aggregate size and texture (Sladonja et al. 2014; Taylor 1974). Water movement and accumulation, aeration and heat content of the soil which greatly influence seed germination, plant growth and yield depend on soil texture (Wu et al. 2011). Emergence of seedlings improved in nursery when the soil aggregate sizes were finer but exceedingly fine particles caused water logging, hindered soil aeration and delayed seeds germination (Taylor 1974).

Nitrogen $(\mathrm{N})$, Phosphorus $(\mathrm{P})$ and Potassium $(\mathrm{K})$ are primary macronutrients always required in largest quantities in soil among the 17 essential mineral elements and are very important for plant growth (Kathpalia and Bhatla 2018). The abundance and availability of these key plant nutrients is dependent on the soil type (Torres-Dorante et al. 2006). Plant growth, quality and yield depend on soil type and nutritional status and thus different plants species require specific soil composition for optimum growth and quality yield (Akamine et al. 2007; Hossain et al. 2011).

Aspilia africana is an important plant of great pharmaceutical and cosmetic interest (Komakech et al. 2019; Okello et al. 2020) and also is one of the most highly browsed on plants by domestic animals including goats, cattle, sheep and rabbits in Africa (Oko et al. 2017). However, there is no scientific literature on its germination and growth limiting its domestication and large-scale cultivation. This is the first study to the best of our knowledge to investigate aspects related to germination and growth of $A$. africana. The current research therefore intended to determine the best commercial soil or soil mixture for the possible smart farm based large-scale cultivation of $A$. africana.

\section{Materials and Method}

Seed material

Mature, ripe and dry seeds of $A$. africana (Fig. 1) collected from Pece in Gulu district, Uganda-East Africa were provided by Natural Chemotherapeutics Research Institute, Uganda. The seeds were transported to Korea Institute of Oriental Medicine, South Korea and stored in a dry storage room at $25 \pm 2^{\circ} \mathrm{C}$ until the start of the experiment.

\section{Commercial soil categories and soil $\mathrm{pH}$ measurement}

Four commercial soil categories (two commercial soils and two commercial soil mixtures) were compared for their potential in the germination and growth of $A$. africana, these were; peat pellet soil (PPS) (Jiffy-7, $33 \mathrm{~mm}$ from Jiffy Products International AS, Norway); horticulture soil (Pungnong Co. Ltd, Republic of Korea) mixed with perlite (Kyungdong ONE Co. Ltd, Republic of Korea) in a 1:1 ratio (HS); horticulture soil with perlite in a 1:1 ratio mixed with peat pellet soil (HS:PPS); horticulture soil with perlite (1:1) mixed with coco peat soil (Sun Cocopeat Co. Ltd, Vietnam) in a 1:1 ratio (HS:CPS). The $\mathrm{pH}$ of the different soil categories were determined using a soil $\mathrm{pH}$ meter (FieldScout SoilStick pH meter, Spectrum Technologies).

\section{Effects of soil category on germination of $A$. africana}

Each of the four commercial soils/ mixtures were filled in cells of a 50 cell plastic planting tray $(52 \mathrm{~cm} \times 26 \mathrm{~cm} \times$ $5 \mathrm{~cm}$ ) and four seeds of $A$. africana were planted in each cell at a depth of about $1 \mathrm{~cm}$. A total of 200 seeds were planted in each soil category in a tray with 4 replicates for each. The planted seeds in the different soils were watered and planting trays with the seeds kept at $25 \pm 2^{\circ} \mathrm{C}$ in a 16 hour photoperiod with light intensity of $33.73 \mu \mathrm{mol} / \mathrm{m}^{2} / \mathrm{s}$ by cool white fluorescent tubes and relative humidity of $70 \%$ in a growth chamber. The planted seeds were watered after every one day until the end to the experiment. The number of seeds germinated after every 48 hours were counted and recorded for each soil category for a period of 20 days when the germination became constant for all

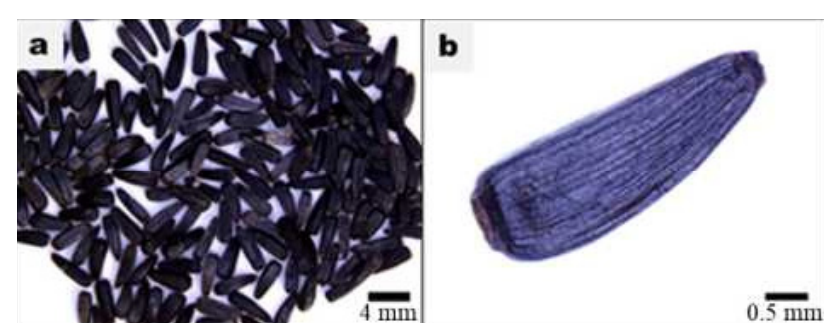

Fig. 1 Seeds of Aspilia africana plants. a) Freshly collected seeds, and b) Detailed morphology of a magnified seed 
soil categories. Seeds were counted as germinated when the hypocotyl lengths were at least $3 \mathrm{~mm}$. Final germination percentage (FGP), mean germination time (MGT), time to $50 \%$ germination $\left(\mathrm{T}_{50}\right)$, mean germination rate (MGR) and germination index (GI) were germination parameters considered for commercial soil effects on germination of $A$. africana seeds. The germination parameters were calculated as follows: FGP $=\frac{N}{N t} \times 100(N$-number of germinated seeds at final count; $N t$ - total number of seeds planted) ; MGT= $\frac{\sum(n t)}{\left(\sum n\right)}$ (n-number of newly germinated $A$. africana seeds at time $t$, and $t$-number of days from planting); $\mathrm{T}_{50}$, calculated according to formula modified by Farooq et al., 2005, $\mathrm{T}_{50}=$ $t_{i}+\frac{\left[\left(\frac{N}{2}-N_{i}\right)\left(t_{j}-t_{i}\right)\right]}{n_{j}-n_{i}}(N$-final number of germinated seeds, $n_{\mathrm{i}}$ and $n_{\mathrm{j}}$ - cumulative number of germinated A. africana seeds counted at time $t_{\mathrm{i}}$ and $t_{\mathrm{j}}$, respectively, when $n_{\mathrm{i}}<\frac{N}{2}$ $\left.<n_{\mathrm{j}}\right) ; \mathrm{MGR}=\frac{\sum(n)}{\left(\sum n t\right)}$ (n-number of newly germinated seeds at time $\mathrm{t}$, and $\mathrm{t}$-number of days from planting); $\mathrm{GI}=\Sigma$ (Gt/Dt) (Gt-number of germinated seeds on day $t$ and $D t$ is time corresponding to Gt in days).

Effects of soil category on leaf chlorophyll contents of $A$. africana

After a period of three months of growth of the A. africana plants, chlorophyll contents of the plant leaves in each soil category were measured using a soil-plant analysis development (SPAD) chlorophyll meter (Minolta Camera, Co., Japan). Six leaves on each plant in each of the soil categories were randomly sampled and for each leaf, four different readings at different points along the leaf length were taken for the average value of the chlorophyll content of that leaf.

Effects of soil category on growth of $A$. africana

The A. africana plants were carefully uprooted after soaking the soil with water and roots thoroughly washed with care. Shoot and root lengths of each of the plants were measured using a stainless steel meter ruler and average for each soil category obtained then the root to shoot length ratios calculated. The number of leaves and roots of each of the A. africana plants were counted and average values obtained for all plants in each of the four soil category. The fresh weights of the $A$. africana plants in the different commercial soils were recorded and thereafter, the plants were dried in an oven maintained at $60^{\circ} \mathrm{C}$ for a period of 48 hours to obtain their dry weights.

Statistical analysis

All data from the experiment were subjected to Analysis of variance (ANOVA) with Tukey's posthoc test for statistical analysis using Prism software (Graph Pad software, Ver. 5. 03 ). The means that were compared were considered statistically significant when $\mathrm{p} \leq 0.05$.

\section{Results}

Soil $\mathrm{pH}$ of the different soil categories

All the commercial soils investigated for growth of $A$. africana were acidic (Fig. 2). The soil pH of PPS at $5.24 \pm 0.235$ was significantly higher $(p<0.05)$ than the rest of the soil categories investigated (Fig. 2). The soil $\mathrm{pH}$ values of HS, HS:PPS and HS:CPS did not differ significantly (Fig. 2).

\section{Effects of soil category on germination of $A$. africana}

Effects of commercial soils on the germination parameters of $A$. africana is showed in Table 1. Final germination percentage (FGP) of $A$. africana seeds was generally very low and did not vary significantly in all soil categories tested. The highest FGP recorded was $15.67 \pm 1.202 \%$ in PPS followed by $15.33 \pm 0.882 \%$ in HS:PPS then $14.00 \pm 0.557 \%$ in HS and least in HS:CPS with $13.33 \pm 0.882 \%$ FGP. The MGT ranged between $7 \sim 10$ days in all the soil categories investigated. The MGT of A. africana seeds in PPS was shortest at $7.64 \pm 0.721$ days and did not significantly differ from the MGT in the rest of the soil categories investigated. The longest MGT of $8.92 \pm 0.421$ days was recorded in HS:CPS. The seeds of $A$. africana germinated

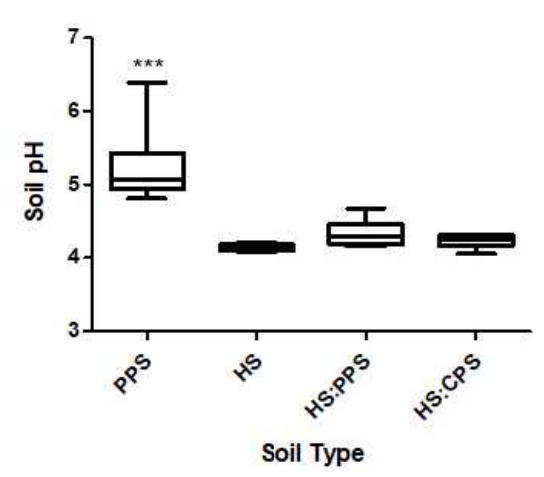

Fig. 2 Soil $\mathrm{pH}$ of the commercial soil categories used to germinate and grow Aspilia africana plants 
Table 1 Results of seed germination of Aspilia africana grown in soils of the different commercial soil categories as per the germination parameters measured

\begin{tabular}{lccccc}
\hline \multirow{2}{*}{ Soil category } & \multicolumn{3}{c}{ Germination parameters } \\
\cline { 2 - 6 } & FGP (\%) & MGT (Days) & MGR & GI & $T_{50}($ Days) \\
\hline PPS & $15.67 \pm 1.202^{\mathrm{a}}$ & $7.64 \pm 0.085^{\mathrm{a}}$ & $0.131 \pm 0.0015^{\mathrm{a}}$ & $4.61 \pm 0.332^{\mathrm{a}}$ & $6.19 \pm 0.050^{\mathrm{a}}$ \\
HS & $14.00 \pm 0.557^{\mathrm{a}}$ & $8.92 \pm 0.421^{\mathrm{a}}$ & $0.113 \pm 0.0057^{\mathrm{a}}$ & $3.09 \pm 0.219^{\mathrm{a}}$ & $7.64 \pm 0.721^{\mathrm{a}}$ \\
HS:PPS & $15.33 \pm 0.882^{\mathrm{a}}$ & $8.22 \pm 0.360^{\mathrm{a}}$ & $0.122 \pm 0.0056^{\mathrm{a}}$ & $4.21 \pm 0.250^{\mathrm{ab}}$ & $6.84 \pm 0.274^{\mathrm{a}}$ \\
HS:CPS & $13.33 \pm 0.882^{\mathrm{a}}$ & $7.95 \pm 0.452^{\mathrm{a}}$ & $0.127 \pm 0.0069^{\mathrm{a}}$ & $3.33 \pm 0.250^{\mathrm{b}}$ & $6.59 \pm 0.369^{\mathrm{a}}$ \\
\hline
\end{tabular}

Means ( \pm standard error) within a column followed by same letter are not significantly different using Tukey's test and $p=0.05$. Note: PPS is peat pellet soil, HS is horticulture soil with perlite, HS:PPS is a mixture of horticulture soil containing perlite with peat pellet soil, HS:CPS is a mixture of horticulture soil containing perlite with coco peat soil, FGP is final germination percentage, MGT is mean germination time, MGR is mean germination rate, GI is germination index, and $\mathrm{T}_{50}$ is time to $50 \%$ germination

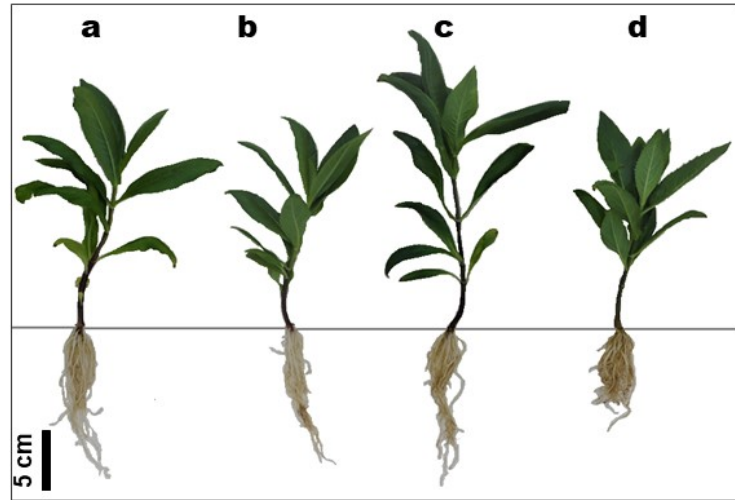

Fig. 3 Comparison of the shoot and root lengths of sampled representative Aspilia africana plants grown in soils of the commercial soil categories: a) Peat pellet soil (PPS), b) Horticulture soil with perlite (HS), c) Mixture of horticulture soil containing perlite and peat pellet soil (HS:PPS), and d) Mixture of horticulture soil containing perlite with coco peat soil (HS:CPS)

fastest in PPS at a MGR of 0.131 followed by HS:CPS at 0.127 then HS:PPS at 0.122 and least in HS with a MGR of 0.113 . There was no significant differences in the MGR of $A$. africana in the different soil categories. Germination index (GI) of $A$. africana differed significantly $(\mathrm{p}<0.05)$. GI was significantly higher in PPS $(\mathrm{p}<0.05)$ at $4.61 \pm 0.332$ compared to the rest of the soil categories. The $\mathrm{T}_{50}$ value for $A$. africana germination did not differ significantly. It was lowest at 6.19 days in PPS and highest at 7.64 days in HS.

\section{Effects of soil category on growth of A. africana}

All A. africana plants grew fast and healthily (Fig. 3). Aspilia africana plants in PPS:HS averagely had the best overall growth based on parameters measured (Fig. 4 (a)-(f)). The plants in HS:PPS had the highest average number of leaves $(18.00 \pm 1.129)$, longest average shoot and root lengths
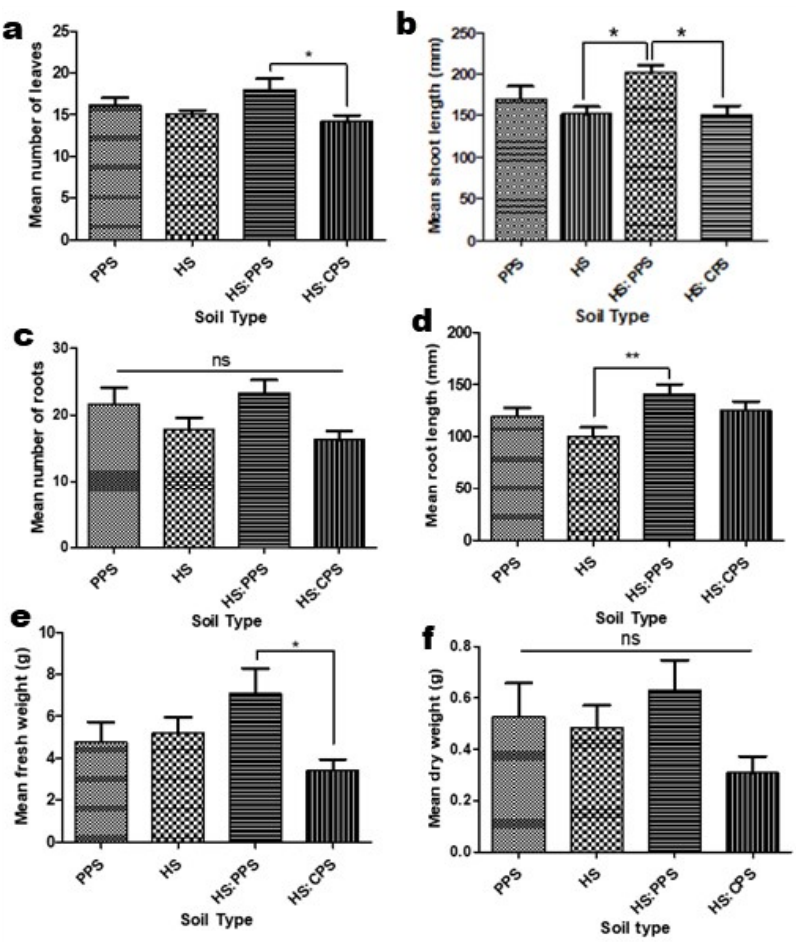

Fig. 4 Growth parameters of Aspilia africana plants in the different commercial soils after three months of growth. a) Number of leaves, b) Shoot lengths, c) Number of roots, d) Root lengths, e) Fresh weight, f) Dry weight. ns indicates no significant difference; * indicates significance at the 0.05 level; ** indicates stronger significance at the 0.025 level

$(202.43 \pm 13.451 \mathrm{~mm}$ and $141.07 \pm 9.967 \mathrm{~mm}$ respectively), highest average number of roots $(23.29 \pm 1.871)$ and highest average fresh and dry weights $(7.08 \pm 1.061 \mathrm{~g}$ and $0.629 \pm$ $0.112 \mathrm{~g}$ respectively) (Fig. 4). The mean number of leaves, shoot lengths and fresh weights differed significantly between HS:PPS and HS:CPS (p < 0.05) (Fig. 4 (a), (b) and (e)). Mean root length of $A$. africana plants in HS was significantly shorter $(\mathrm{p}<0.05)$ than for plants in HS:PPS (Fig. 4 (d)). The $A$. africana plants in PPS had averagely the second highest mean number of leaves and roots, shoot and root 


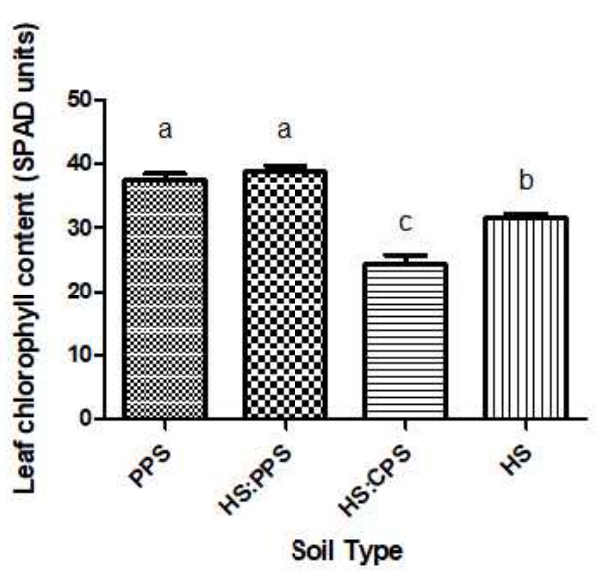

Fig. 5 Leaf chlorophyll content of Aspilia africana plants in soils of the different commercial soil categories after three months of growth

lengths and dry weight although these did not significantly differ from $A$. africana plants in the rest of the soil categories (Fig. 4). There was no significant differences in number of roots and mean dry weights of $A$. africana plants in all the soil categories investigated (Fig. 4 (c) and (f)).

Effects of soil category on leaf chlorophyll contents of $A$. africana

Mean chlorophyll contents in leaves of $A$. africana in the different commercial soils differed significantly $(\mathrm{p}<0.05)$ (Fig. 5). Mean chlorophyll contents of $A$. africana leaves in HS:PPS and PPS were significantly higher than $A$. africana plant leaves in HS and HS:CPS (Fig. 5). The least mean chlorophyll content was $24.12 \pm 1.659$ in leaves of A. africana plants in HS:CPS and was significantly lower than those of $A$. africana plants in all soil categories $(\mathrm{p}<0.05)$ (Fig. 5).

\section{Discussion}

Germination parameters of seeds are influenced by a number of environmental and internal seed factors (Bareke 2018). Final germination percentage (FGP) and mean germination rate (MGR) of $A$. africana seeds were generally very low with no significant differences in the commercial soil categories investigated (Table 1). Although the harvested seeds of $A$. africana seemed mature, the low FGP and MGR could have been due to a dormancy period of the seeds attributed to embryo immaturity and therefore, the seeds needed to undergo a period of full maturity. Seeds of some plants after harvest may have to be stored for a while to undergo some biochemical and enzymatic changes in order to achieve maturity and improve germinability (Bareke 2018). So, the Seeds of $A$. africana could have needed to have been stored for a longer time before planting; its after ripening period could have been longer. Since the seeds of A. africana were harvested from the wild, there is a possibility that the seeds were attacked by pathogens contributing to a reduction their FGP and MGR. A number of studies showed that seed borne pathogens reduced germination percentage and rate and increased seedling mortality (Cram and Fraedrich 2010). Cram and Fraedrich (2010) emphasizes that pathogenic fungi infects seeds internally destroying the endosperm and embryo thus affecting seed germination. Seed size is a vital physical factor that affects germination and growth (Steiner et al. 2019). Small seeds such as those of $A$. africana are very susceptible to pathogen attack compared to larger seeds (Pringle et al. 2007). Given the size of $A$. africana seeds, they are very tiny and a burial depth of $1.5 \mathrm{~cm}$ in the soil could have been deep enough to hinder the germination of the A. africana seeds. Benvenuti et al. (2001) noted that very tiny seeds had their germination completely inhibited at even very shallow burial depths. In a study on L. texensis, Schaal (1980) found that seed size was positively correlated to germination. Seeds that are large unlike tiny seeds have large energy reserve for their early growth and development and subsequently have higher germination rates and percentage (Skogen et al. 2010). Significant differences in the germination parameters of $A$. africana except for GI did not exist thus indicating similarity in physical soil attributes of all the different commercial soil categories such as adequate porosity enabling sufficient oxygen penetration to the seeds. Sufficient gaseous exchange between the seeds and the external environment increases seed respiratory activity enabling rapid germination (Benvenuti 2003; Valdés-Rodríguez et al. 2013).

The germination of $A$. africana in the different commercial soils seemed not dependent on $\mathrm{pH}$ as there was no significant differences in germination parameters between PPS and the rest of the commercial soil categories (Table 1). This was possibly because the soil $\mathrm{pH}$ value range in all commercial soil categories was within ideal range for germination of $A$. africana. This is contrary to a research by Sladonja et al. (2014) who found that a small variation in $\mathrm{pH}$ among the soil chemical parameters measured greatly influenced germination of pyrethrum. According to Sladonja et al. (2014), although soil nutrient quantity and organic matter were very important for growth of pyrethrum, they were not very relevant for its germination. Likewise, with the environmental conditions such as temperature and 
humidity kept at almost constant levels, the germination of A. africana seeds depended more upon the nature of the soil particles in the different commercial soil categories tested and less on soil organic matter and nutritional contents in the soil.

A number of factors influence the quality, growth and yield of plants and these include soil type and soil nutritional contents (Ohshiro et al. 2016). Morgan and Connolly (2013) stated that deficiency in soil nutrients results in stunted plant growth, plant tissue death and yellowing of plant leaves. The plants grown in all the commercial soil categories investigated grew healthily without signs of soil nutrient deficiencies such as yellowing of leaves (Fig. 3). This therefore meant that all the commercial soils investigated were sufficiently supplied with plant nutritional requirements essential for their growth and development. Nevertheless, just as it was exhibited by $A$. africana planted in different categories of commercial soils, particular plants grow better in certain types of soils.

Aspilia africana planted in HS:PPS recorded over all highest increase in growth parameters amongst all the commercial soil categories investigated. This could be attributed to a much higher amount of particular mineral nutrients such as nitrogen, potassium and phosphorus in HS:PPS soil than the rest that were ideal for boosting growth of $A$. africana. Ohshiro et al. (2016) noted that greater N contents in the soil boosted growth parameters of Amaranthus tricolorlines and resulted in healthiest plants compared to plants in soils with lower nitrogen contents. In other similar studies, $\mathrm{N}$ was also reported to be more important for growth of vegetative plant parts than other plant nutrients (Akamine et al. 2007; Hossain et al. 2011). A number of studies confirmed that plant growth is greatly boosted by soil phosphorus and potassium levels (Akamine et al. 2007; Ogoke et al. 2004). There could have also been more abundant $\mathrm{K}$ in HS:PPS compared to the rest of the commercial soil categories tested. This is because $\mathrm{K}$ is a catalysts that regulates the functioning of many of the plant minerals besides promoting efficient uptake of $\mathrm{N}$ (Ohshiro et al. 2016) and thus its sufficient quantity could have greatly boosted the growth of $A$. africana in HS:PPS above the others. The increased biomass recorded in A. africana plants in HS:PPS could be attributed to higher photosynthetic rate leading to more accumulation of organic matter within the plant tissues evidenced by greater chlorophyll contents in the leaves of the plants in HS:PPS soil. Chlorophyll, the main photosynthetic material reflects the photosynthetic ability of plant (Zulkarnaini et al. 2019). Buttery and Buzzell (1977) showed a close relationship between photosynthetic rate and chlorophyll content in Soya beans. Increase in chlorophyll contents increased the rate of carbon dioxide assimilation and dry matter accumulation (Liu et al. 2019). A study by Gang et al. (1992) indicated that chlorophyll content in tartary buckwheat was positively correlated to its biomass and yield. In another study, rate of photosynthesis was closely related to chlorophyll contents which was found to be positively correlated to chlorophyll content index of leaves (Parry et al. 2014). Liu et al. (2019) demonstrated that chlorophyll content index could be used for modelling above ground biomass in plants. The higher fresh and dry weights of $A$. africana plants in HS:PPS could be attributed to greater photosynthetic capacity of the plants due to increased higher chlorophyll contents that led to greater organic matter accumulation. Further, leaf chlorophyll contents can be used to indicate leaf nutrient deficiencies (Ali et al. 2017) and soil N deficiency (Kalacska et al. 2015). Thus, an indication that $\mathrm{N}$ contents in HS:CPP were lowest among the commercial soil categories investigated in this study since it had the plants had the lowest chlorophyll contents, least growth parameter and lowest average fresh and dry weights.

Chlorophyll, a vital plant photosynthetic pigment largely determines photosynthetic capacity and thus plant growth (Li et al. 2018). Chlorophyll harvests sun light at different wave lengths for the excitation of electrons that drive the formation of chemical energy and adenine dinucleotide phosphate (Croft et al. 2017). At a large scale, soil composition plays an important role in regulating plant chlorophyll contents ( $\mathrm{Li}$ et al. 2018). This could be attributed to the fact that chlorophyll synthesis need many elements including nitrogen and phosphorus that are supplied from the soil (Fredeen et al. 1990). Although a number of factors influence chlorophyll contents in plants ( $\mathrm{Li}$ et al. 2018), the difference observed in A. africana plant leaves could be attributed to the differences in vital elements supply from the soil essential for its synthesis. This therefore meant that $A$. africana plants in HS:PPS were more richly supplied with mineral elements such as $\mathrm{N}$ and $\mathrm{P}$ thus greater leaf chlorophyll contents.

The growth of $A$. africana seemed favoured by low soil pH. All the commercial soil categories investigated had relatively low $\mathrm{pH}$, with best overall growth in HS:PPS with a $\mathrm{pH}$ of $4.33 \pm 0.0765$. Soil $\mathrm{pH}$ is an important variable since it influences a number of soil properties and properties that affect plant growth (Gentili et al. 2018). Karthika et al. (2018) notes that at low $\mathrm{pH}$, most micronutrients are readily available to plants thus favouring their general growth. 


\section{Conclusion}

Although there was no significant differences in any of the A. africana plant growth parameters between PPS and HS:PPS, the growth of $A$. africana plants was generally better in HS:PPS among all commercial soil categories investigated. Aspilia africana plants in HS:PPS had highest mean number of leaves and roots, lengths of shoots and roots and average fresh and dry weights. Chlorophyll contents in A. africana plants in HS:PPS and PPS were significantly higher than those in HS and HS:CPS indicating possibly a greater photosynthetic potential of plants in these soils. Significant differences in the germination parameters of $A$. africana plants except for GI in all commercial soil categories did not exist indicating similarity in the soil attributes that influence seed germination such as soil porosity. The germination percentage of $A$. africana in all the commercial soil categories investigated were very low and below $20 \%$. It is not conclusive why the germination in all commercial soil categories was very low and thus we recommend an exclusive study in this regard.

\section{Acknowledgements}

This study was supported under the framework of International Cooperation Program (Korea-South Africa Cooperative Research Project for Excavation of Candidate Resources of Complementary and Alternative Medicine) managed by National Research Foundation of Korea (grant no. 2017 093655 and KIOM: D17470). Additionally, this work was also supported by Development of Foundational Techniques for the Domestic Production of Herbal Medicines (K18405), Development of Sustainable Application for Standard Herbal Resources (KSN2013320), Korea Institute of Oriental Medicine through the Ministry of Science and ICT, Republic of Korea. The authors greatly thank Mr. Gang Roggers (National Agricultural Research Organization, Uganda) for collecting the seeds of the plant.

\section{Conflict of interest}

The authors declare that they have no conflict of interest.

\section{References}

Ajeigbe K, Onifade A, Omotoso D, Enitan S, Olaleye S (2014) Anti-ulcerogenic activity of Aspilia africana leaf extract: roles of gastric acid, oxidative stress and neutrophil infiltration. African Journal of Biomedical Research 17(3):193-201

Akamine H, Hossain MA, Ishimine Y, Yogi K, Hokama K, Iraha Y, Aniya Y (2007) Effects of application of N, P and K alone or in combination on growth, yield and curcumin content of turmeric (Curcuma longa L.). Plant production science 10 (1):151-154

Ali M, Al-Ani A, Eamus D, Tan DK (2017) Leaf nitrogen determination using non-destructive techniques $-\mathrm{A}$ review. Journal of Plant Nutrition 40(7):928-953

Bareke T (2018) Biology of seed development and germination physiology. Adv Plants Agric Res 8(4):336-346

Benvenuti S (2003) Soil texture involvement in germination and emergence of buried weed seeds. Agronomy Journal 95 (1):191-198

Benvenuti S, Macchia M, Miele S (2001) Quantitative analysis of emergence of seedlings from buried weed seeds with increasing soil depth. Weed Science 49(4):528-535

Buttery B, Buzzell R (1977) The relationship between chlorophyll content and rate of photosynthesis in soybeans. Canadian Journal of Plant Science 57(1):1-5

Cram M, Fraedrich S (2010) Seed diseases and seedborne pathogens of North America. Tree Planters' Notes 53(2):35-44

Croft H, Chen JM, Luo X, Bartlett P, Chen B, Staebler RM (2017) Leaf chlorophyll content as a proxy for leaf photosynthetic capacity. Global change biology 23(9):3513-3524

Fredeen AL, Raab TK, Rao IM, Terry N (1990) Effects of phosphorus nutrition on photosynthesis in Glycine max (L.) Merr. Planta 181(3):399-405

Gang Z, Yu T, Banghua Y, Xiaolei L A study on the relationship between the chlorophyll content and the yield of plant of tartary buckwheat. In: Proceedings of the 5th International Symposium on Buckwheat, Taiyuan, China, 1992. pp 20-26

Gentili R, Ambrosini R, Montagnani C, Caronni S, Citterio S (2018) Effect of soil $\mathrm{pH}$ on the growth, reproductive investment and pollen allergenicity of Ambrosia artemisiifolia L. Frontiers in plant science 9:1335

Hossain M, Hanafi M, Jol H, Jamal T (2011) Dry matter and nutrient partitioning of kenaf ('Hibiscus cannabinus' L.) varieties grown on sandy bris soil. Australian Journal of Crop Science 5(6):654

Kalacska M, Lalonde M, Moore T (2015) Estimation of foliar chlorophyll and nitrogen content in an ombrotrophic bog from hyperspectral data: Scaling from leaf to image. Remote Sensing of Environment 169:270-279

Karthika K, Rashmi I, Parvathi M (2018) Biological functions, uptake and transport of essential nutrients in relation to plant growth. In: Plant nutrients and abiotic stress tolerance. Springer, pp 1-49

Kathpalia R, Bhatla SC (2018) Plant mineral nutrition. In: Plant physiology, development and metabolism. Springer, pp 37-81

Komakech R, Matsabisa MG, Kang Y (2019) The wound healing potential of Aspilia africana (Pers.) CD Adams (Asteraceae). Evidence-Based Complementary and Alternative Medicine 2019 
Li Y, He N, Hou J, Xu L, Liu C, Zhang J, Wang Q, Zhang X, Wu $X$ (2018) Factors influencing leaf chlorophyll content in natural forests at the biome scale. Frontiers in Ecology and Evolution 6:64

Liu C, Liu Y, Lu Y, Liao Y, Nie J, Yuan X, Chen F (2019) Use of a leaf chlorophyll content index to improve the prediction of above-ground biomass and productivity. PeerJ 6:e6240

Morgan Já, Connolly Eá (2013) Plant-soil interactions: nutrient uptake. Nature Education Knowledge 4(8):2

Ogoke I, Togun A, Carsky R, Dashiell K (2004) Effect of phosphorus fertilizer on soyabean pod yield in the Guinea Savanna. Nigeria Agricultural Journal 35:40-48

Ohshiro M, Hossain MA, Nakamura I, Akamine H, Tamaki M, Bhowmik PC, Nose A (2016) Effects of soil types and fertilizers on growth, yield, and quality of edible Amaranthus tricolor lines in Okinawa, Japan. Plant Production Science 19 (1):61-72

Okello D, Kang Y (2019a) Ethnopharmacological potentials of Warburgia ugandensis on antimicrobial activities. Chinese journal of integrative medicine: 1-8

Okello D, Kang Y (2019b) Exploring antimalarial herbal plants across communities in Uganda based on electronic data. Evidence-Based Complementary and alternative medicine 2019

Okello D, Lee J, Kang Y (2020) Ethnopharmacological Potential of Aspilia africana for the Treatment of Inflammatory Diseases. Evidence-Based Complementary and Alternative Medicine 2020

Oko O, Asuquo O, Agiang E, Osim E (2017) Neuroendocrine and behavioural responses of Japanese quails to dietary Aspilia africana leaf meal and extracts. Journal of Livestock Science (ISSN online 2277-6214) 8:43-51

Parry C, Blonquist Jr JM, Bugbee B (2014) In situ measurement of leaf chlorophyll concentration: analysis of the optical/absolute relationship. Plant, cell \& environment 37(11):2508-2520

Pringle EG, Alvarez-Loayza P, Terborgh J (2007) Seed characteristics and susceptibility to pathogen attack in tree seeds of the Peruvian Amazon. Plant Ecology 193(2):211-222

Schaal BA (1980) Reproductive capacity and seed size in Lupinus texensis. American Journal of Botany 67(5):703-709

Skogen KA, Senack L, Holsinger KE (2010) Dormancy, small seed size and low germination rates contribute to low recruitment in Desmodium cuspidatum (Fabaceae). The Journal of the Torrey Botanical Society 137(4):355-365

Sladonja B, Krapac M, Ban D, Užila Z, Dudaš S, Dorčić D (2014) Effect of soil type on pyrethrum seed germination. Journal of Plant Protection Research

Steiner F, Zuffo AM, Busch A, Sousa TdO, Zoz T (2019) Does seed size affect the germination rate and seedling growth of peanut under salinity and water stress? Pesquisa Agropecuária Tropical 49

Taylor M (1974) The effect of soil aggregate size on seedling emergence and early growth. East African Agricultural and Forestry Journal 40(2):204-213

Torres-Dorante LO, Claassen N, Steingrobe B, Olfs HW (2006) Fertilizer-use efficiency of different inorganic polyphosphate sources: effects on soil $\mathrm{P}$ availability and plant $\mathrm{P}$ acquisition during early growth of corn. Journal of Plant Nutrition and Soil Science 169(4):509-515

Valdés-Rodríguez OA, Sánchez-Sánchez O, Pérez-Vázquez A (2013) Effects of soil texture on germination and survival of non-toxic Jatropha curcas seeds. Biomass and Bioenergy 48:167-170

Wu Y, Huang M, Gallichand J (2011) Transpirational response to water availability for winter wheat as affected by soil textures. Agricultural Water Management 98(4):569-576

Zulkarnaini Z, Sakimin S, Mohamed M, Jaafar H Relationship between chlorophyll content and soil plant analytical development values in two cultivars of fig (Ficus carica L.) as brassinolide effect at an open field. In: IOP Conference Series: Earth and Environmental Science, 2019. vol 1. IOP Publishing, p 012025 